\title{
Differentiation Among Potyviruses Infecting Sweet Potato Based on Genus- and Virus-Specific Reverse Transcription Polymerase Chain Reaction
}

\author{
D. Colinet, M. Nguyen, J. Kummert, and P. Lepoivre, Faculté Universitaire des Sciences Agronomiques, Unité \\ de Phytopathologie, 13 Avenue Maréchal Juin, 5030 Gembloux, Belgium, and Feng Zu Xia, Upland Crops Re- \\ search Institute, Guangzhou, China
}

\begin{abstract}
Colinet, D., Nguyen, M., Kummert, J., Lepoivre, P., and Xia, F. Z. 1998. Differentiation among potyviruses infecting sweet potato based on genus- and virus-specific reverse transcription polymerase chain reaction. Plant Dis. 82:223-229.

Knowledge of virus diseases affecting sweet potato has been complicated due to the frequent occurrence of mixed infections and difficulties in isolating and purifying sweet potato viruses. A combined assay of reverse transcription and polymerase chain reaction (PCR) utilizing degenerate genus-specific primers POT1 and POT2 was applied to 18 sweet potato clones from China. The primers were designed to amplify the variable $5^{\prime}$ terminal region of the potyvirus coat protein gene. Molecular analysis of the amplified fragments identified the Chinese strains of sweet potato feathery mottle virus (SPFMV-CH), sweet potato latent virus (SPLV-CH), and sweet potato virus $\mathrm{G}$ (SPVG-CH). Among the detected potyviruses, a distantly related strain of SPFMV-CH, tentatively named SPFMV-CH2, was identified in sweet potatoes from China. On the basis of sequence identity, SPFMV-CH2 was closely related to the common (-C) strain of that virus. Identification of a closely related strain of SPVG-CH in one sweet potato clone from China further illustrated the usefulness of broad-spectrum PCR for detecting uncharacterized viruses. The acquisition of sequence information permitted the design of virus-specific primers for detecting and differentiating SPFMV, SPLV, and SPVG.
\end{abstract}

Sweet potato (Ipomoea batatas L.) is an important crop that feeds millions of people in developing countries. Although this versatile plant originated in South America, China is currently the largest producer with about $80 \%$ of the world production (10). Numerous sweet potato diseases presumed to be caused by viruses have been described $(4,15)$, but their etiology is still unclear. The lack of progress in virus identification and classification has been mainly due to the frequent occurrence of mixed infections and synergistic complexes in sweet potato $(4,15)$. These obstacles, together with difficulties inherent to the isolation and purification of viruses from sweet potato, led us to consider polymerase chain reaction (PCR) technology to identify and characterize members of the genus Potyvirus infecting sweet potato.

Depending on the choice of primers, PCR aids in the detection of a single virus

Corresponding author: D. Colinet; 32-81-622432; Fax 32-81-610126

E-mail: colinet@fsagx.ac.be

The nucleotide sequence data reported in this paper have been submitted to the EMBL nucleotide sequence database and have been assigned the accession numbers Z98942 (SPFMV-CH), AJ001440 (SPFMV-CH2), and Z83314 (SPVG$\mathrm{CH} 2$ ).

Accepted for publication 4 November 1997.

Publication no. D-1997-1208-01R

(C) 1998 The American Phytopathological Society species or many members of a group or family of related viruses. Knowledge of conserved viral sequences has allowed the design of oligonucleotide primers for use in PCR amplification and rapid identification of uncharacterized potyviruses $(8,12,16)$. The usefulness of broad-specific PCR for rapid characterization of plant viruses has also been demonstrated for carlaviruses (2), geminiviruses $(18,19)$, and luteoviruses (17). Since genome and coat protein sequence data are among the major criteria for identification and classification of the Potyviridae (20-23), broad-spectrum PCR and molecular analysis of the amplified fragments represent a rapid method for obtaining valuable sequence information.

The recent increase in potyvirus sequence data has permitted the design of genus-specific degenerate primers for the amplification of sequences of new or uncharacterized potyviruses infecting sweet potato $(5,8)$. Three distinct potyviruses were identified in multiply infected sweet potato clones from China (8). Sweet potato feathery mottle virus (SPFMV-CH) was closely related to the russet crack (-RC) strain of SPFMV (5). Sweet potato latent virus (SPLV-CH) was unambiguously assessed as a distinct potyvirus (7). A previously unidentified virus was reported and tentatively named sweet potato virus $G$ (SPVG-CH) (8). The cloning and sequence analysis of the $3^{\prime}$ end of the genome of SPVG-CH further revealed a close relationship with SPFMV (6). Genus-specific
PCR thus appeared to be the most suitable method to obtain information on the identity and characteristics of potyviruses infecting sweet potato.

This broad-spectrum strategy has been applied to 18 sweet potato clones from China and the usefulness of sequence information in sweet potato virus identification and classification demonstrated. Specific primers have been designed for the molecular detection of the potyviruses infecting sweet potato, providing for additional epidemiological studies to be conducted on the newly identified SPVG.

\section{MATERIALS AND METHODS}

Virus isolates, plant materials and RNA extraction. I. batatas clones, listed in Table 1, originated in the Guangdong province of China. The sweet potato clones from Taiwan (TN339 and TN440), Kenya (KB109), and Togo (Georgia Jet) were received courtesy of $\mathrm{J}$. Vetten (Federal Biological Research Center for Agriculture and Forestry, Braunschweig, Germany). Two other sweet potato clones originated from Cambodia (Camb) and Gabon (Gab).

Total RNA was extracted from $100 \mathrm{mg}$ of symptomatic leaves following a procedure improved from the single-step RNA isolation method (3), using Trizol (Gibco BRL, Life Technologies, England). Messenger RNA (mRNA) was purified using Oligotex-dT (Qiagen, Qiagen Inc., Chatsworth, CA) according to the manufacturer's instructions. Single-stranded cDNA synthesis was performed from $100 \mathrm{ng}$ of mRNA, using the SuperScript preamplification system for first-strand cDNA synthesis (Gibco BRL).

PCR amplification with potyvirusspecific primers. The potyvirus-specific thermal cycling scheme was performed in a 50- $\mu$ l reaction buffer (Boehringer, Mannheim, Germany) containing $200 \mu \mathrm{M}$ each of dATP, dCTP, dGTP, and dTTP; $0.1 \mathrm{nM}$ each of POT1 and POT2 primers (Fig. 1); and 1 unit of Taq DNA polymerase (Boehringer). Forty reaction cycles were performed as follows: template denaturation at $94^{\circ} \mathrm{C}$ for $30 \mathrm{~s}$, primer annealing at $42^{\circ} \mathrm{C}$ (cycles $1-5$ ) or $60^{\circ} \mathrm{C}$ (cycles 6-40) for $60 \mathrm{~s}$, and DNA synthesis at $72^{\circ} \mathrm{C}$ for 90 s. A final 5-min elongation step at $72^{\circ} \mathrm{C}$ was performed at the end of the 40 cycles. Amplification products were cloned in the pCRII plasmid (TA cloning kit, Invitrogen, Carlsbad, CA), which allowed direct 
cloning of PCR products without digestion with restriction enzymes.

Amplified fragments were analyzed in $1 \%$ agarose gels and subsequently transferred to nylon membranes (Hybond- ${ }^{+}$, Amersham International, England). Digoxigenin labeling and hybridization were performed using the DIG DNA labeling and DIG luminescent detection kits (Boehringer) according to the manufacturer's instructions.

PCR screening of transformed colonies. The PCR screening of transformed colonies was performed with ICFMV1 and 2 primers and SPVGA and $\mathrm{B}$ primers (Table 2). The primers were designed from the sequences of SPFMV-CH (5) and SPVG-CH (6), respectively. Amplification of the recombinant plasmids was performed in a 50- $\mu$ l reaction buffer (Amersham) containing $200 \mu \mathrm{M}$ each of dATP, dCTP, dGTP, and dTTP; $0.1 \mathrm{nM}$ each of the respective upstream and downstream primers; and 1 unit of Taq DNA polymerase (Amersham). Transformed colonies were selected with a toothpick and transferred to the PCR reaction buffer. The following thermal cycling scheme was followed for 35 cycles: template denaturation at $94^{\circ} \mathrm{C}$ for $30 \mathrm{~s}$, primer annealing at $60^{\circ} \mathrm{C}$ for $1 \mathrm{~min}$, and DNA synthesis at $72^{\circ} \mathrm{C}$ for $1 \mathrm{~min}$.

Cloning of the $3^{\prime}$ end of the genome of SPFMV-CH, SPFMV-CH2, and SPVGCH2. The rapid amplification of cDNA ends (RACE) method (11) was used to clone a cDNA fragment corresponding to the 3' terminal region of the genome of SPFMV-CH, SPFMV-CH2, and SPVG$\mathrm{CH} 2$. Single stranded cDNA was synthesized from $100 \mathrm{ng}$ of mRNA isolated from I. nil infected with SPFMV-CH and from sweet potato clones GN169 (SPFMV-CH2) and GN144 (SPVG-CH2), using the Gibco BRL Superscript preamplification system and the hybrid $\mathrm{dT}_{17}$-adapter primer (5' GACTCGAGTCGACAGCGATTTTTTTTTTTTTTTTT3') (11). Amplification was carried out using the adapter primer (5' GACTCGAGTCGA-CAGCG 3') (11) and the specific primers MPFMVCH1, MPFMVCH2, and VGRACE1 (Fig. 1), respectively. Amplification was carried out in a 20- $\mu$ l reaction buffer (Boehringer) containing $50 \mu \mathrm{M}$ each of dATP, dCTP, dGTP, and dTTP; $0.05 \mathrm{nM}$ each of adapter and specific primers; and 1 unit of Taq DNA polymerase (Boehringer). The fol- lowing thermal cycling scheme was followed for 35 cycles: template denaturation for $10 \mathrm{~s}$ at $94^{\circ} \mathrm{C}$, annealing for $30 \mathrm{~s}$ at $52^{\circ} \mathrm{C}$, and elongation for $1 \mathrm{~min}$ at $72^{\circ} \mathrm{C}$.
Sequence analysis of the amplified fragments. Because of the low fidelity of Taq DNA polymerase, which may lead to misincorporations, the sequences of the
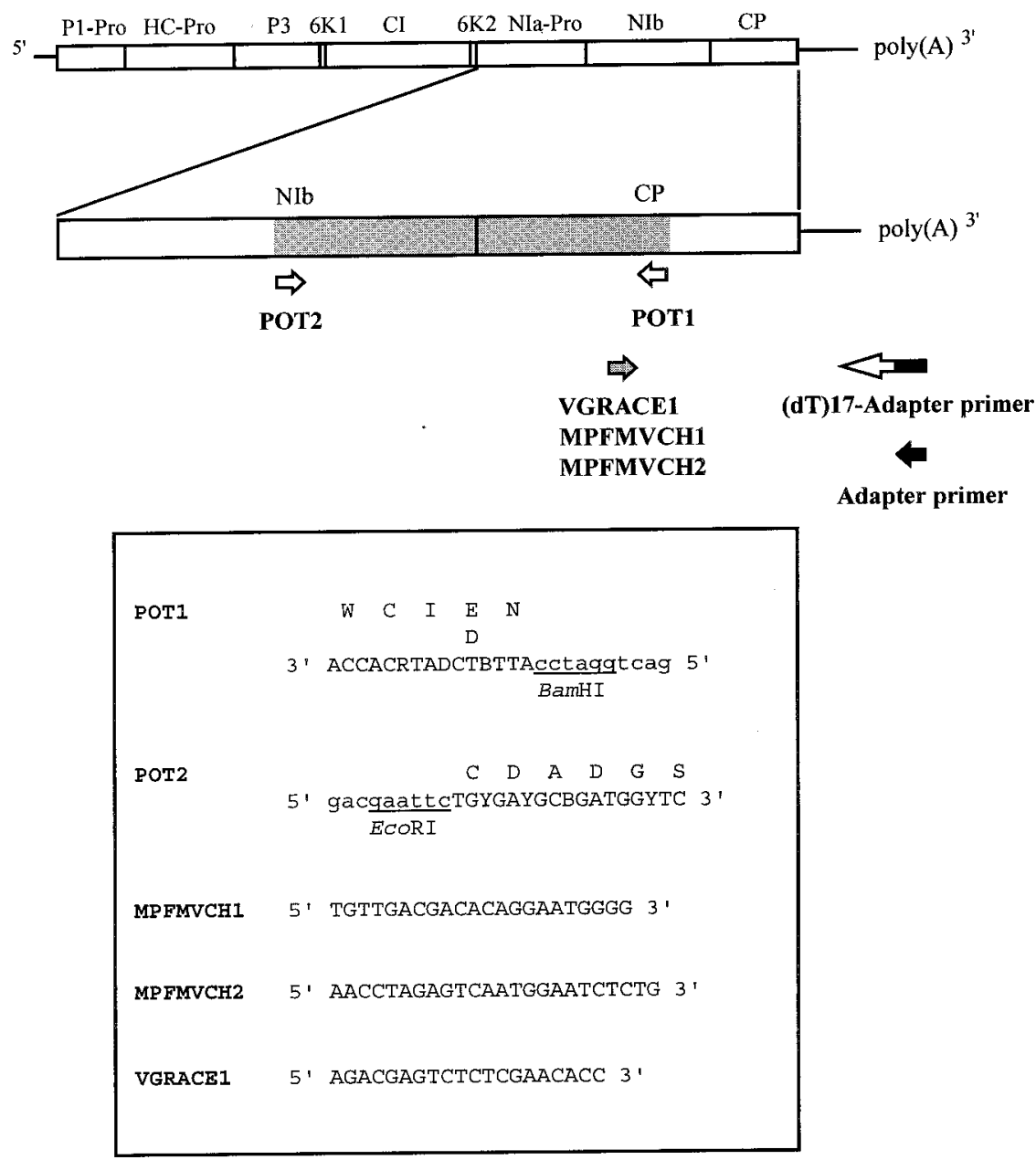

Adapter primer

Fig. 1. Genetic map of the potyvirus genome, showing the relative positions and the sequence of the two degenerate primers POT1 and POT2. Letters above the nucleotide sequences of the primers represent the amino acid sequences of the conserved regions in the potyviral polyprotein. Lowercase letters represent nucleotides not derived from the viral sequences. Also shown are the relative positions of the rapid amplification of cDNA ends $(\mathrm{dT})_{17}$-adapter and adapter primers and position and sequence of the specific primers designed from the known sequence of the $5^{\prime}$ terminal part of the coat protein gene of SPFMV-CH, SPFMV-CH2, and SPVG-CH2. Primer MPFMVCH1 corresponds to nucleotides 447-468 of the sequence of SPFMV-CH, primer MPFMVCH2 to nucleotides 302-325 of the sequence of SPFMV-CH2, and primer VGRACE1 to nucleotides 490-509 of the sequence of SPVG-CH2. The hatched box represents the part of the genome amplified by reverse transcriptase polymerase chain reaction with degenerate primers POT1 and POT2. P1-Pro $=$ first protein/protease, HC-Pro $=$ helper component/protease, $\mathrm{P} 3=$ third protein, $6 \mathrm{~K} 1=6 \mathrm{~K}$ peptide, $\mathrm{CI}=$ cytoplasmic inclusion protein, $6 \mathrm{~K} 2=$ second $6 \mathrm{~K}$ peptide, $\mathrm{NIa}-\mathrm{Pro}=$ nuclear inclusion a protein/protease, $\mathrm{NIb}=$ nuclear inclusion $\mathrm{b}$ protein (RNA polymerase), $\mathrm{CP}=$ coat protein.

Table 1. Distribution of SPFMV (-CH and -CH2), SPLV-CH, and SPVG (-CH and -CH2) in 18 sweetpotato clones ${ }^{\mathrm{a}}$ from China as determined by polymerase chain reaction and hybridization

\begin{tabular}{|c|c|c|c|c|c|c|c|c|c|c|c|c|c|c|c|c|c|c|}
\hline Virus & 1 & 2 & 3 & 4 & 5 & 6 & 7 & 8 & 9 & 10 & 11 & 12 & 13 & 14 & 15 & 16 & 17 & 18 \\
\hline $\begin{array}{l}\text { SPFMV-CH } \\
\text { SPLV-CH }\end{array}$ & & & & & & + & + & + & & & & & + & & & & + & $\begin{array}{l}+ \\
+\end{array}$ \\
\hline $\begin{array}{l}\text { SPVG-CH } \\
\text { SPFMV-CH2 }\end{array}$ & + & + & + & + & + & + & + & + & + & $\begin{array}{l}+ \\
+\end{array}$ & + & & + & + & + & + & & $\begin{array}{l}+ \\
+\end{array}$ \\
\hline
\end{tabular}

SPVG-CH2

a $1=$ Xiao, $2=$ GN718, $3=208,4=$ GN144, $5=$ Jucai, $6=$ GN58, $7=865,8=$ GN7, $9=740,10=$ GN169, $11=$ Guang, $12=1023,13=461,14=$ Zhou, $15=132,16=743,17=$ Yub, $18=$ GN1. 
PCR products were deduced from three independent clones. Complete nucleotide sequences were obtained either by subcloning amplified fragments after cleavage with restriction enzymes or by using specific primers derived from the sequences. Double-stranded DNA sequencing by the dideoxy chain termination method was performed using T7 DNA polymerase according to the manufacturer's instructions (Pharmacia, Inc., Piscataway, NJ). Sequence analyses employed DNASIS and University of Wisconsin Genetics Computer Group sequence analysis software package version 8.0 (9). Sequence comparisons were performed with SPFMVcommon (-C) (1), -ordinary (-O) (14), -RC (1), and -severe (-S) (13); SPVG-CH (6); SPLV-CH and -T (7); and all potyviruses found in Genbank and EMBL databases.

Amplification with virus-specific primers. The sequence of the specific primers MPCOM, MPVG, MPFMVCH1, MPFMVCH2, MPLV1, and MPLV2 are given in Table 2. Single-stranded cDNA was synthesized from $100 \mathrm{ng}$ of mRNA. Amplification was performed in a $20-\mu \mathrm{l}$ reaction buffer (Boehringer), containing 50 $\mu \mathrm{M}$ each of dATP, dCTP, dGTP, and dTTP; $0.05 \mathrm{nM}$ each of upstream and downstream primers; and 1 unit of Taq DNA polymerase (Boehringer), as follows for 30 cycles: template denaturation at $94^{\circ} \mathrm{C}$ for $10 \mathrm{~s}$, primer annealing at $62^{\circ} \mathrm{C}$ for $30 \mathrm{~s}$, and DNA synthesis at $72^{\circ} \mathrm{C}$ for $45 \mathrm{~s}$.

\section{RESULTS}

Amplification with potyvirus-specific primers POT1 and POT2. The PCR procedure using POT1 and POT2 was designed to amplify the variable $5^{\prime}$ terminal half of the coat protein gene of potyviruses $(5,8)$, and was applied to the analysis of the diversity of potyviruses infecting 18 sweet potato clones from the Guangdong province of China (Table 1).

Amplification of the variable $5^{\prime}$ terminal region of the coat protein gene yielded one to three fragments $(1.30,1.35$, and 1.45 $\mathrm{kbp}$ ), depending on the sweet potato clone. No PCR products were visible for sweet potato clones 1023, Zhou, or 743 in ethidium bromide stained gels. Previously amplified fragments for SPFMV-CH (1.35 kbp), SPLV-CH (1.30 kbp), and SPVG-CH $(1.45 \mathrm{kbp})$ were labeled with digoxigenin (Boehringer). A series of hybridizations were performed after transfer of amplified fragments from agarose gels to nylon membranes. SPFMV-CH was identified in 6 of the 18 sweet potato clones (GN58, 865, GN7, 461, Yub, and GN1), SPLV$\mathrm{CH}$ in one sweet potato clone (GN1), and SPVG-CH in all sweet potato clones but two (1023 and Yub) (Table 1). PCR amplification with ICFMV1 and 2 primers, MPLV1 and 2 primers (designed from the known sequence of SPLV-CH and -T, see below) and SPVGA and B primers specific for each of the three potyviruses (Table 2) confirmed the hybridization results.

Table 2. Primer sequences and expected size of polymerase chain reaction product for each primer pair when used to amplify the appropriate virus template

\begin{tabular}{llcc}
\hline Primer name & Primer sequence & Target & Expected size (bp) \\
\hline ICFMV1 $^{\text {a }}$ & AATAACTGAGGTCGTTGATCCGGAGGACC & 403 \\
ICFMV2 $^{\text {b }}$ & TCCATTCAATAAGATCCCCATTCCTG & SPFMV-CH & \\
SPVGB $^{\mathrm{b}}$ & AACGTGCATCATCAGTCTGC & SPVG-CH & 402 \\
MPCOM $^{\mathrm{b}}$ & GAAAGTACCAACGCTACCAG & SPFMV and SPVG & \\
MPVG $^{\mathrm{a}}$ & GGCTCGATCACGAACCAAAAAGGC & SPVG & $581^{\mathrm{c}}$ \\
MPFMVCH1 $^{\mathrm{a}}$ & TATTGGATCATGCTGTCCCCACA & SPFMV-CH type & $700^{\mathrm{c}}$ \\
MPFMVCH2 $^{\mathrm{a}}$ & TGTTGACGACACAGGAATGGGG & SPFMV-CH2 type & $359^{\mathrm{c}}$ \\
MPLV1 $^{\mathrm{a}}$ & AACCTAGAGTCAATGGAATCTCTG & SPLV & 337 \\
MPLV2 $^{\mathrm{b}}$ & GACTAACACACCAACCCAGCCA & & \\
\hline
\end{tabular}

a Viral sense.

${ }^{\mathrm{b}}$ Complementary sense.

c Primer used with MPCOM.

Table 3. Pairwise percent amino acid sequence identities between the complete coat protein of members of the genus Potyvirus infecting sweetpotato

\begin{tabular}{|c|c|c|c|c|c|c|c|c|c|}
\hline & SPVG-CH2 & SPFMV-CH & SPFMV-CH2 & SPFMV-C & SPFMV-O & SPFMV-RC & SPFMV-S & SPLV-CH & SPLV-T \\
\hline SPVG-CH & 93.5 & 70.7 & 69.9 & 70.4 & 71.7 & 72.3 & 72.0 & 57.9 & 57.0 \\
\hline SPVG-CH2 & & 72.0 & 70.2 & 70.7 & 72.9 & 73.6 & 73.3 & 58.9 & 58.0 \\
\hline SPFMV-CH & & & 81.5 & 81.9 & 96.5 & 96.2 & 95.2 & 59.4 & 58.0 \\
\hline SPFMV-CH2 & & & & 97.4 & 82.1 & 83.4 & 83.1 & 61.9 & 60.5 \\
\hline SPFMV-C & & & & & 82.5 & 84.1 & 83.8 & 60.4 & 59.0 \\
\hline SPFMV-O & & & & & & 95.6 & 95.2 & 59.7 & 58.3 \\
\hline SPFMV-RC & & & & & & & 99.1 & 60.1 & 58.7 \\
\hline SPFMV-S & & & & & & & & 60.1 & 58.7 \\
\hline SPLV-CH & & & & & & & & & 94.5 \\
\hline SPLV -T & & & & & & & & & \\
\hline
\end{tabular}

Table 4. Pairwise percent amino acid sequence identities between the conserved core of the coat protein of members of the genus Potyvirus infecting sweetpotato

\begin{tabular}{|c|c|c|c|c|c|c|c|c|c|}
\hline & SPVG-CH2 & SPFMV-CH & SPFMV-CH2 & SPFMV-C & SPFMV-O & SPFMV-RC & SPFMV-S & SPLV-CH & SPLV-T \\
\hline SPVG-CH & 95.8 & 80.6 & 80.1 & 80.6 & 80.6 & 81.0 & 81.0 & 67.1 & 66.2 \\
\hline SPVG-CH2 & & 81.9 & 81.6 & 81.0 & 81.9 & 83.4 & 83.4 & 68.5 & 67.6 \\
\hline SPFMV-CH & & & 88.9 & 89.4 & 98.6 & 99.1 & 99.1 & 68.1 & 66.7 \\
\hline SPFMV-CH2 & & & & 99.5 & 88.9 & 89.4 & 89.4 & 69.9 & 68.1 \\
\hline SPFMV-C & & & & & 89.4 & 89.8 & 89.8 & 69.4 & 68.1 \\
\hline SPFMV-O & & & & & & 98.6 & 98.6 & 68.1 & 66.7 \\
\hline SPFMV-RC & & & & & & & 100 & 68.5 & 67.1 \\
\hline SPFMV-S & & & & & & & & 68.5 & 67.1 \\
\hline SPLV-CH & & & & & & & & & 98.6 \\
\hline SPLV-T & & & & & & & & & \\
\hline
\end{tabular}


Identification of SPFMV-CH2 and SPVG-CH2. The 1.35-kbp fragment amplified from sweet potato clone GN169 did not hybridize with the SPFMV-CH probe. Similarly, the $1.45-\mathrm{kbp}$ fragment amplified from sweet potato clone GN144 hybridized only slightly with the SPVG-CH probe.
PCR products were cloned in the pCRII plasmid (Invitrogen, Carlsbad, CA). Transformed colonies were screened by PCR with the ICFMV 1 and 2 primers and SPVG A and B primers, specific for SPFMV-CH and SPVG-CH, respectively. A $1.35-\mathrm{kbp}$ fragment (from sweet potato

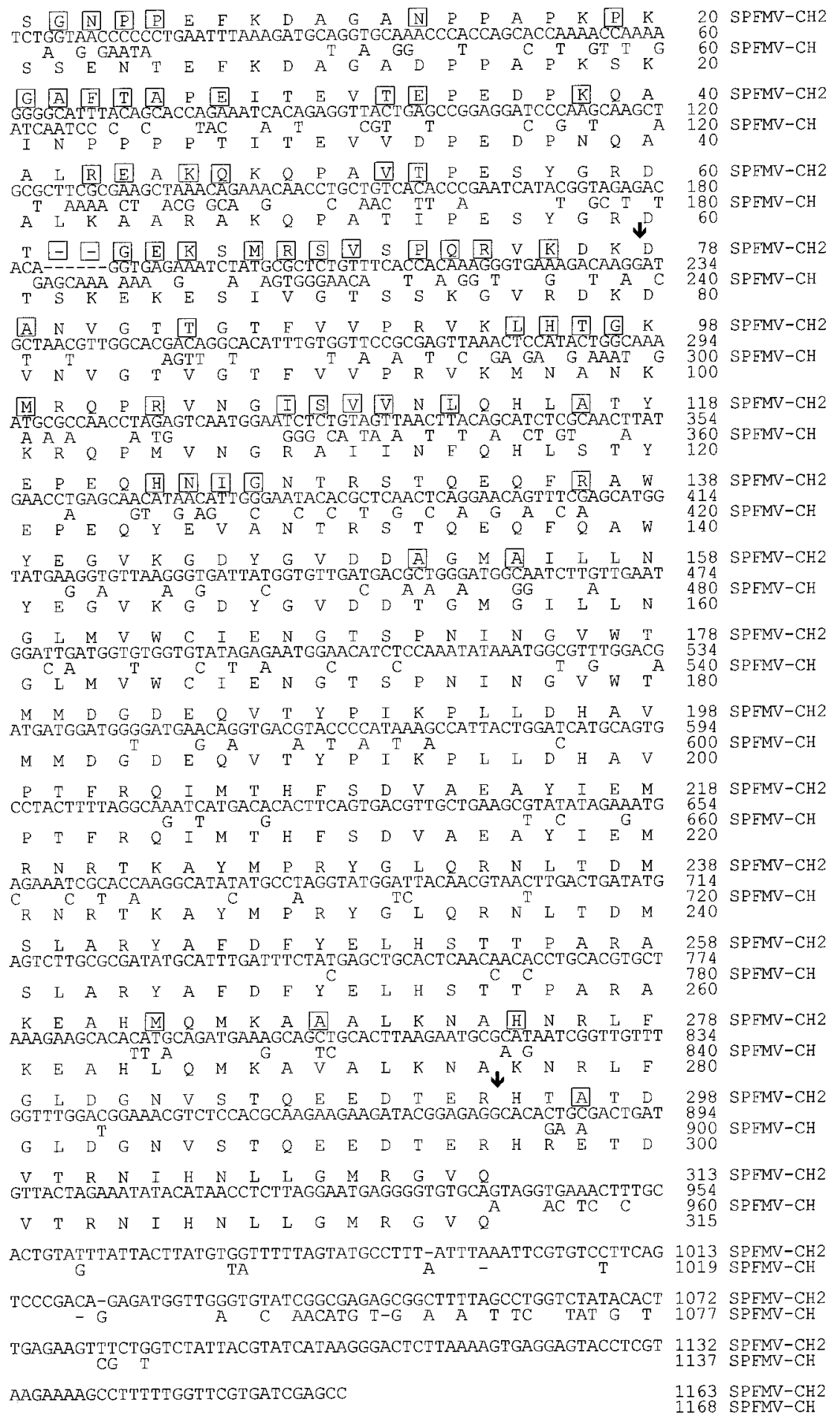

Fig. 2. Sequences of the SPFMV-CH2 and SPFMV-CH coat protein gene and 3' untranslated region. The nucleotide sequence of SPFMV-CH2 is shown. Nucleotides of the SPFMV-CH sequence that differ from SPFMV-CH2 are shown below the SPFMV-CH2 sequence. The predicted amino acid sequences of the coat protein of SPFMV-CH2 and SPFMV-CH are presented above and below the corresponding nucleotide sequence, respectively. Amino acids of the SPFMV-CH2 sequence that differ from SPFMV-CH are boxed. An arrow indicates the first and the last amino acid of the potyvirus coat protein conserved core (equivalent to $\mathrm{D}^{33}$ to $\mathrm{R}^{248}$ in PVY). clone GN169) and a 1.45-kbp fragment (from sweet potato clone GN144), respectively distinct from SPFMV-CH and SPVG-CH, were identified. The two virus isolates were tentatively named SPFMV$\mathrm{CH} 2$ and SPVG-CH2, respectively. Hybridization studies identified SPFMV-CH2 in two sweet potato clones (GN169 and GN1) and SPVG-CH2 in one sweet potato clone only (GN144) (Table 1).

The sequence was determined for the $5^{\prime}$ terminal region of the coat protein gene of SPFMV-CH2 (Fig. 2; nucleotides 1-486) and SPVG-CH2 (Fig. 3; nucleotides 1612). SPVG-CH2 shared $89.2 \%$ amino acid sequence identity with SPVG-CH in the N-terminal half of the coat protein. SPFMV-CH2 shared $67.3 \%$ amino acid sequence identity with SPFMV-CH in the N-terminal half of the coat protein, whereas the identity with SPFMV-C was greater than $95 \%$.

Sequence analysis of the $3^{\prime}$ end of the genome of SPFMV-CH, SPFMV-CH2, and SPVG-CH2. RACE method (11) was used to amplify a cDNA fragment corresponding to the $3^{\prime}$ terminal region of SPFMV-CH, SPFMV-CH2, and SPVG$\mathrm{CH} 2$ genomes. The complete nucleotide sequences of the coat protein gene and the 3' untranslated region of SPFMV-CH and $-\mathrm{CH} 2$ are presented in Figure 2. The sequences include an open reading frame (ORF) coding for the viral coat protein of 315 and 313 amino acids, respectively, followed by a 3' untranslated region of 223 and 224 nucleotides, respectively. (Fig. 2). The sequence of SPFMV-CH2 was two amino acids shorter than that of SPFMV-C (Fig. 2) and other strains of SPFMV.

Sequence of the 3' terminal part of SPVG-CH2 genome was aligned with that of SPVG-CH (Fig. 3). There is an open reading frame $(\mathrm{ORF})$ corresponding to the coat protein gene and extending for 1065 nucleotides. The ORF has the capacity to encode 355 amino acids. It is followed by an untranslated region of 223 nucleotides and a poly(A) tail (Fig. 3).

Pairwise percent sequence identities between the complete coat protein and the conserved coat protein core of SPVG-CH and - $\mathrm{CH} 2$, SPFMV-CH and - $\mathrm{CH} 2$, and members of the genus Potyvirus infecting sweet potato are shown on Tables 3 and 4. SPVG-CH2 shares 93.5 and $95.8 \%$ amino acid sequence identity in the coat protein and coat protein core, respectively, with SPVG-CH. The SPFMV-CH2 complete coat protein shares $81.5-83.4 \%$ amino acid sequence identity with that of SPFMV-CH, $-\mathrm{O},-\mathrm{RC}$, and $-\mathrm{S}$, whereas the identity with SPFMV-C is much higher $(97.4 \%)$. The amino acid sequence identities in the coat protein core between SPFMV-CH2 and SPFMV-CH, -O, -RC, and -S range from 88.9 to $89.4 \%$. The sequence identities between SPFMV and SPVG in the coat protein core range from 80.1 to $81.0 \%$. In contrast, a search of the Genbank and 
EMBL databases with the coat protein core of SPFMV and SPVG showed identity levels less than $70 \%$ with SPLV and all previously sequenced potyviruses. Dendrograms of sequence relationship generated from the alignment of the complete coat protein and the conserved coat protein core are shown in Figure 4.

Differentiation among three sweet potato potyviruses in mixed infections based on virus-specific RT-PCR. The 3' genomic nucleotide sequences of SPFMV$\mathrm{C},-\mathrm{CH},-\mathrm{CH} 2,-\mathrm{O},-\mathrm{RC}$, and -S; SPVG-CH and - $\mathrm{CH} 2$; and SPLV-CH and -T were compared and six primers were designed (Table 2). MPCOM primer is specific to SPFMV and SPVG. MPVG primer is specific to both $-\mathrm{CH}$ and $-\mathrm{CH} 2$ strains of SPVG. MPFMVCH1 was designed to specifically amplify SPFMV-CH, -O, -RC, or -S (defined as SPFMV-CH type), when combined with MPCOM, whereas MPFMVCH2 is specific to SPFMV-C and $-\mathrm{CH} 2$ (defined as SPFMV-CH2 type). Two primers, MPLV1 and MPLV2, were designed to amplify either strain of SPLV. The length of the amplified fragment was predicted as follows: 581 bp for SPVG (MPCOM + MPVG), 700 bp for SPFMV$\mathrm{CH}$ type (MPCOM + MPFMVCH1), 859 bp for SPFMV-CH2 type (MPCOM + MPFMVCH2), and 337 bp for SPLV (MPLV1 + MPLV2).

The RT-PCR procedure utilizing virusspecific primers was evaluated on the 18 sweet potato clones from China, and the results obtained in Table 1 were confirmed in ethidium bromide stained gels. Six additional sweet potato clones from Taiwan (TN339 and TN340), Kenya (KB 109), Togo (Georgia Jet), Cambodia (Camb), and Gabon (Gab) were also evaluated. Positive controls consisted in SPFMV-infected $I$. nil, SPLV-infected I. nil, and SPVGinfected sweet potato clone GN144. SPFMV-CH was amplified from KB109, Georgia Jet, and Camb, whereas SPFMVCH2 was amplified from TN340, KB109, Georgia Jet, and Camb (Fig. 5). SPVG was amplified only from the positive control GN144, whereas SPLV was amplified from KB109 (Fig. 5).

\section{DISCUSSION}

Potyvirus-specific PCR and further sequence analysis of the $5^{\prime}$-terminal variable region of the coat protein gene was performed on 18 sweet potato clones from China. Two previously unreported virus isolates, tentatively named SPFMV-CH2 and SPVG-CH2, were identified. Partial sequence data demonstrated that SPFMV$\mathrm{CH} 2$ and SPVG-CH2 are closely related to SPFMV-C and SPVG-CH, respectively. SPFMV-CH2, however, shares only $69.8 \%$ sequence identity with SPFMV-CH in the $\mathrm{N}$-terminal half of the coat protein. This illustrates the difficulty in using partial sequence information to determine whether viruses such as SPFMV-CH and - $\mathrm{CH} 2$ should be considered as closely related, distinct viruses, or distantly related strains.

Relationships between SPFMV-CH and $-\mathrm{CH} 2$ were refined by a closer analysis of the complete coat protein coding region.
On the basis of sequence identities, the SPFMV strains can indeed be subgrouped (Fig. 4). Based on the degree of coat protein and coat protein core sequence identity between SPFMV-CH and - $\mathrm{CH} 2$ (81.5 and

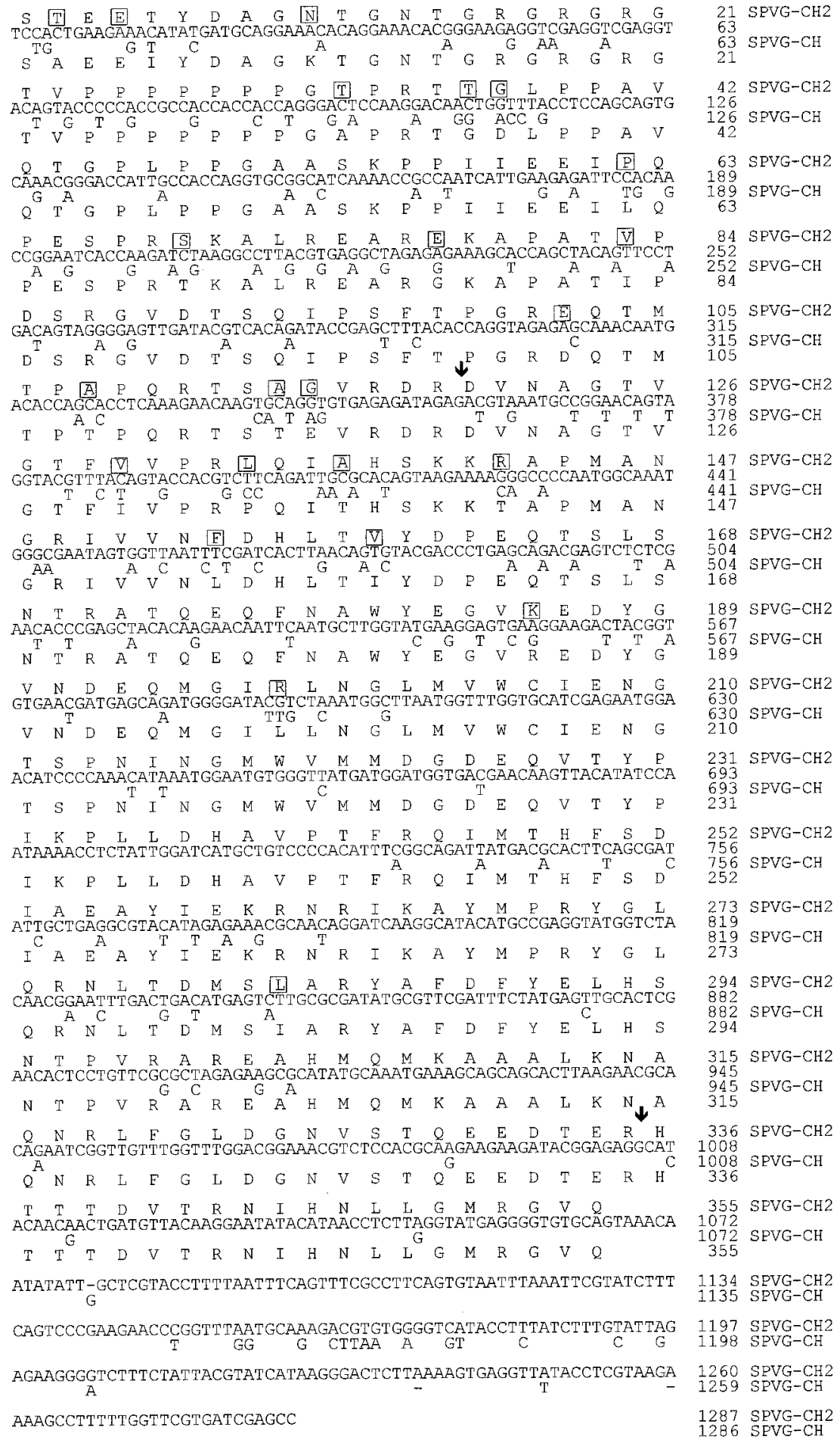

Fig. 3. Sequences of the SPVG-CH2 and SPVG-CH coat protein gene and 3' untranslated region. The complete nucleotide sequence of SPVG-CH2 is shown. Nucleotides of the SPVG-CH sequence that differ from SPVG-CH2 are shown below the SPVG-CH2 sequence. The predicted amino acid sequences of the coat protein of SPVG-CH2 and SPVG-CH are presented above and below the corresponding nucleotide sequence, respectively. Amino acids of the SPVG-CH2 sequence that differ from SPVG-CH are boxed. An arrow indicates the first and the last amino acid of the potyvirus coat protein conserved core (equivalent to $\mathrm{D}^{33}$ to $\mathrm{R}^{248}$ in PVY). 


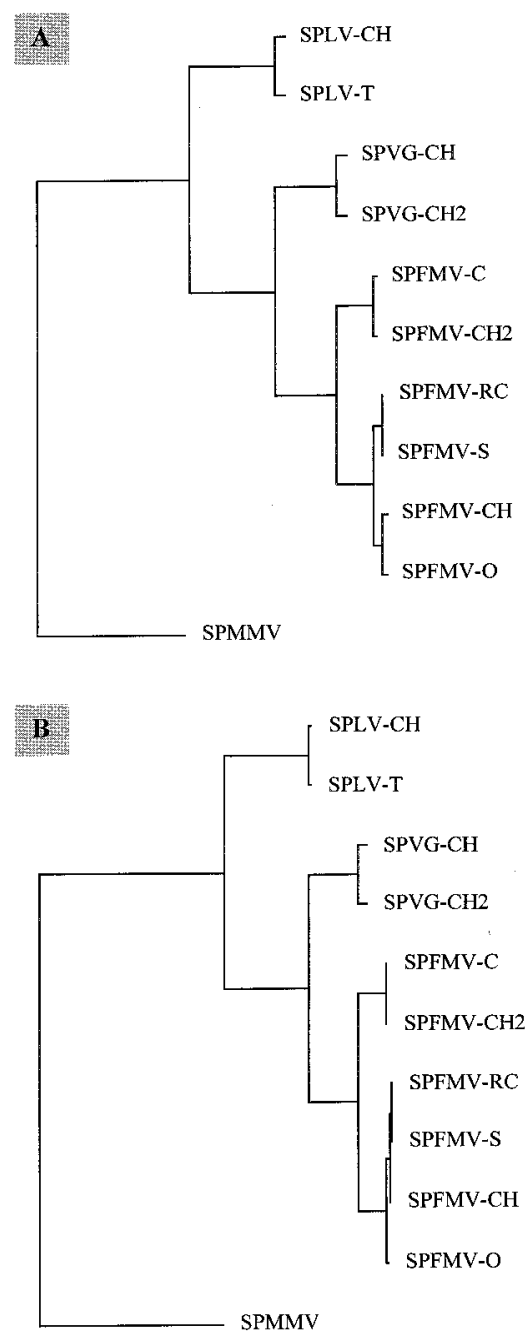

Fig. 4. Taxonomic relationship between the complete coat protein (A), and the conserved coat protein core (B) of SPFMV-C, - CH, -CH2, - O, - RC and -S; SPVG-CH and -CH2; and SPLV-CH and -T. The sweetpotato mild mottle ipomovirus (SPMMV) was taken as an outgroup. The sequence relationship dendrogram was produced using ClustalV.

$88.9 \%$, respectively), both isolates can be considered to be distantly related strains of the same virus. On the other hand, SPFMV-CH, - RC, -O, and -S are closely related to each other and share more than $95 \%$ identity in the coat protein. Such sequence analyses also clearly showed that SPVG should be considered as closely related to, though distinct from SPFMV (7), reflecting a more recent evolutionary relationship between both viruses (Fig. 4).

Genus-specific PCR and subsequent molecular analysis of amplified regions thus comprised a powerful method for the rapid identification and differentiation of potyviruses infecting sweet potato, and appeared as the most suitable method for viruses difficult to purify and/or occurring in mixed infections. The dendrograms of sequence relationships generated from the alignment of the complete coat protein and the coat protein core constitute valuable tools for the rapid assessment of the dis- tinct/closely related/strain status of borderline cases such as SPFMV-CH and SPFMV-CH2 or SPFMV and SPVG.

The development of molecular and serological detection methods would allow epidemiological studies to be performed on sweet potato-infecting members of the genus Potyvirus, particularly SPVG. Specific primers for detecting and differentiating SPFMV (-CH and -CH2), SPLV, and SPVG were designed from the 3' genomic nucleotide sequences of these viruses. Analysis of the distribution of the potyviruses infecting sweet potato in the clones from the Guangdong province of China outlined the complexity of potyvirus infection in some of the clones, and the apparent ubiquitous nature of the newly identified SPVG compared to SPFMV and SPLV. The analysis of six sweet potato clones from Africa and Asia confirmed the worldwide distribution of SPFMV compared to SPVG. The ability to detect this previously unknown virus should shed light on its world-

\section{A. SPVG}

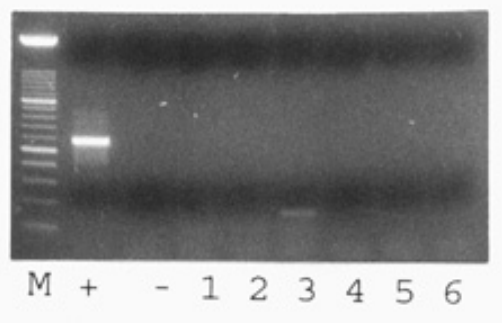

B. SPFMV


Fig. 5. Analysis of products amplified from total sweetpotato RNA with SPVG-specific primers (A), SPFMV-specific primers (B), and SPLV-specific primers (C). $M=100$ bp DNA ladder (Boehringer). $+=$ Positive control. $-=$ Negative control. $1=$ Sweetpotato clone TN339. 2 = Sweetpotato clone TN340. $3=$ Sweetpotato clone KB109. 4 = Sweetpotato clone Georgia Jet. $5=$ Sweetpotato clone Camb. $6=$ Sweetpotato clone Gab.

wide distribution and importance in the etiology of sweet potato diseases.

\section{ACKNOWLEDGMENTS}

We thank J. Vetten (Federal Biological Research Center for Agriculture and Forestry, Braunschweig, Germany) for helpful discussions and for providing sweet potato clones from Taiwan, Kenya and Togo. This work was financially supported by EEC (Project STD3 TS3-CT91-0013).

\section{LITERATURE CITED}

1. Abad, J. A., Conkling, M. A., and Moyer, J. W. 1992. Comparison of the capsid protein cistron from serologically distinct strains of sweet potato feathery mottle virus (SPFMV). Arch. Virol. 126:147-157.

2. Badge, J., Brunt, A., Carson, R., Dagless, E., Karamagioli, M., Phillips, S., Seal, S., Turner, R., and Foster, G. D. 1996. A carlavirusspecific PCR primer and partial nucleotide sequence provides further evidence for the recognition of cowpea mild mottle virus as a whitefly transmitted carlavirus. Eur. J. Plant Pathol. 102:305-310. 
3. Chomczynski, P., and Sacchi, N. 1987. Single-step method of RNA isolation by acid guanidium thiocyanate-phenol-chloroform extraction. Anal. Biochem. 162:156-159.

4. Clark, C. A., and Moyer, J. W. 1988. Compendium of sweet potato diseases. APS Press. The American Phytopathological Society, St. Paul, MN.

5. Colinet, D., and Kummert, J. 1993. Identification of a sweet potato feathery mottle virus isolate from China (SPFMV-CH) by the polymerase chain reaction with degenerate primers. J. Virol. Methods 45:149-159.

6. Colinet, D., Kummert, J., and Lepoivre, P. 1994. The complete nucleotide sequences of the coat protein cistron and the 3' non-coding region of a newly-identified potyvirus infecting sweet potato, as compared to those of sweet potato feathery mottle virus. Arch. Virol. 139:327-336.

7. Colinet, D., Kummert, J., and Lepoivre, P. 1997. Evidence for the assignment of two strains of SPLV to the genus Potyvirus based on coat protein and 3' non-coding region sequence data. Virus Res. 49:91-100.

8. Colinet, D., Kummert, J., Lepoivre, P., and Semal, J. 1994. Identification of distinct potyviruses in mildly infected sweetpotato by the polymerase chain reaction with degenerate primers. Phytopathology 84:65-69.

9. Devereux, J., Haeberli, P., and Smithies, O. 1984. A comprehensive set of sequence analysis programs for the VAX. Nucleic Acids Res. 12:387-395.

10. FAO (Food and Agriculture Organization)
1994. Production Yearbook, Rome, Italy.

11. Frohman, M. A. 1990. RACE: Rapid amplification of cDNA ends. Pages 28-38 in: PCR protocols: A guide to methods and applications. M. A. Innis, D. H. Gelfand, J. J. Sninsky, and T. J. White, eds. Academic Press, San Diego.

12. Langeveld, S. A., Dore, J. M., Memelink, J., Derks, A. F. L. M., van der Vlugt, C. I. M., Asjes, C. J., and Bol, J. F. 1991. Identification of potyviruses using the polymerase chain reaction with degenerate primers. J. Gen. Virol. 72:1531-1541.

13. Mori, M., Sakai, J., Kimura, T., Usugi, T., Hayashi, T., Hanada, K., and Nishiguchi, M. 1995. Nucleotide sequence analysis of two nuclear inclusion body and coat protein genes of a sweetpotato feathery mottle virus severe strain (SPFMV-S) genomic RNA. Arch. Virol. 140:1473-1482.

14. Mori, M., Usugi, T., Hayashi, T., and Nishiguchi, M. 1994. Nucleotide sequence at the 3'-terminal region of sweetpotato feathery mottle virus (ordinary strain, SPFMV-O) RNA. Biosci. Biotech. Biochem. 58:965-967.

15. Moyer, J. W., and Salazar, L. F. 1989. Virus and virus-like diseases of sweet potato. Plant Dis. 73:451-455.

16. Pappu, S. S., Brand, R., Pappu, H. R., Rybicki, E. P., Gough, K. H., Frenkel, M. J., and Niblett, C. L. 1993. A polymerase chain reaction method adapted for selective amplification and cloning of 3' sequences of potyviral genomes: Application to dasheen mosaic vi- rus. J. Virol. Methods 41:9-20.

17. Robertson, N. L., French, R., and Gray, S. M. 1991. Use of group-specific primers and the polymerase chain reaction for the detection and identification of luteoviruses. J. Gen. Virol. 72:1473-1477.

18. Rojas, M. R., Gilbertson, R. L., Russell, D. R., and Maxwell, D. P. 1993. Use of degenerate primers in the polymerase chain reaction to detect whitefly transmitted geminiviruses. Plant Dis. 77:340-347.

19. Rybicki, E. P., and Hughes, F. L. 1990. Detection and typing of maize streak virus and other distantly related geminiviruses of grasses by polymerase chain reaction amplification of a conserved viral sequence. J. Gen Virol. 71:2519-2526.

20. Rybicki, E. P., and Shukla, D. D. 1992. Coat protein phylogeny and systematics of potyviruses. Pages 139-170 in: Potyvirus taxonomy (Arch. Virol. [Suppl 5]). O. W. Barnett, ed. Springer, New York.

21. Shukla, D. D., and Ward, C. W. 1989. Identification and classification of potyviruses on the basis of coat protein sequence data and serology. Arch. Virol. 106:171-200.

22. Shukla, D. D., Ward, C. W., and Brunt, A. A 1994. The Potyviridae. CAB International, Wallingford.

23. Ward, C. W., McKern, N. M., Frenkel, M. J., and Shukla, D. D. 1992. Sequence data as the major criterion for potyvirus classification. Pages 283-297 in: Potyvirus taxonomy (Arch. Virol. [Suppl 5]). O.W. Barnett, ed. Springer, New York. 